Int. J. Electrochem. Sci., 13 (2018) 3812 - 3826

International Journal of

ELECTROCHEMICAL

SCIENCE

www.electrochemsci.org

\title{
Electrical and Dielectric Properties of Copper Ion Conducting Solid Polymer Electrolytes Based on Chitosan: CBH Model for Ion Transport Mechanism
}

\author{
Shujahadeen B. Aziz ${ }^{1,2, *}$, Omed Gh. Abdullah ${ }^{1,2}$, Salah R. Saeed ${ }^{3}$ and Hameed M. Ahmed ${ }^{1}$ \\ ${ }^{1}$ Advanced Polymeric Materials Research Lab., Department of Physics, College of Science, University \\ of Sulaimani, Qlyasan Street, Sulaimani, 46001, Kurdistan Regional Government, Iraq \\ ${ }^{2}$ Komar Research Center (KRC), Komar University of Science and Technology, Sulaimani, 46001, \\ Kurdistan Regional Government, Iraq \\ ${ }^{3}$ Charmo Research Center, Charmo University, Peshawa Street, Chamchamal, Sulaimani, Kurdistan \\ Regional Government, Iraq \\ *E-mail: shujaadeen78@yahoo.com, rshujahadeenaziz@gmail.com
}

doi: $10.20964 / 2018.04 .10$

Received: 20 November 2017 / Accepted: 20 January 2018 / Published: 6 March 2018

Copper ion-conducting polymer electrolytes based on chitosan (CS) were prepared using solution-cast technique. The CS host polymer was complexed with different weight percent copper iodide (CuI) salt. Effect of frequency, temperature and copper ion concentration on the electrical and dielectric properties has been studied. The high value of dielectric constant at low frequency is an evidence for the presence of space charge polarization. The AC conductivity at higher frequency region obeys a Jonschers power law. Three regions were distinguished in the ac conductivity spectra of the solid polymer electrolyte films. The frequency exponent $(S)$ was estimated for the high-frequency regions. Analysis of frequency exponent $(S)$ at various temperatures suggested the correlated barrier hopping $(\mathrm{CBH})$ model for ion transport mechanism at high temperatures. The results of the present work, reveals that to get deep insight about the conduction mechanism the frequency exponent $(S)$ at different temperature must be studied. The estimated value of dc conductivity obtained from the plateau region of ac conductivity spectra seem to be close to those calculated from the bulk resistance. The electrical modulus analysis shows the non-Debye type conductivity relaxation.

Keywords: polymer electrolytes; dielectric properties; electrical conductivity; ionic transport mechanism; electric modulus

$\underline{\text { FULL TEXT }}$ 
(C) 2018 The Authors. Published by ESG (www.electrochemsci.org). This article is an open access article distributed under the terms and conditions of the Creative Commons Attribution license (http://creativecommons.org/licenses/by/4.0/). 